
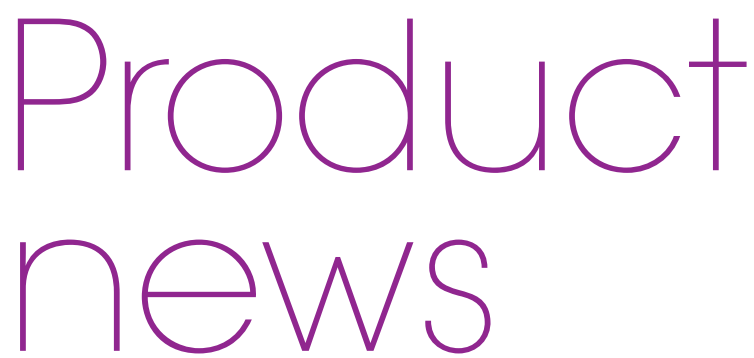

Product news is provided as a service to readers using text and images from

the manufacturer, supplier or distributor and does not imply endorsement

by BDJ Team. Normal and prudent research should be exercised before

purchase or use of any product mentioned.

\section{UNIQUE INSIGHTS INTO THE NATION'S BRUSHING HABITS}

Award-winning dental care innovation Brushlink has passed its 10,000 sessions milestone, showing that since its soft launch in November last year it is already having positive impact on the oral health of the nation. The 10,000 sessions equate to around 12 million individual brushing data samples, which together give a unique insight to the brushing habits of Brushlink users while providing them with feedback on how to further improve their brushing technique.

Brushlink is the first device of its kind that can track and coach people on brushing frequency, duration and angles while making this data available to dentists if consented - and it works with any toothbrush, manual or electric. Brushlink has also been built to provide a brushing score each time it is used, which makes it phone in the bathroom. great for families - parents and kids can compete with each other to see who is the 'best brusher'. The score is displayed along with 'in-brush' coaching tips and hints via a Bluetooth connection to a smartphone app; however, it also stores data for up to three months in case the user does not have a

The data collected by the device is used by the user's dentist to create a bespoke dental hygiene plan based on their brushing habits. The care plan is automatically uploaded to the device, helping to make brushing even more effective and efficient and thereby improving oral health.

Dr Dev Patel, CEO and Founder of Brushlink and an award-winning dentist, commented: 'The amount and quality of our data is giving us a real insight into the brushing habits of the nation - showing

where they are with their brushing routine at a certain point and how they are improving their technique over time. We are working on research relating to the data we are gathering, and early indications show that using Brushlink can reduce dental plaque (the cause of dental decay) by as much as 40 percent.'
A STAGED \section{APPROACH}

At the British Dental Conference and Dentistry Show, Philips supported a main-stage lecture by Dr Ben Atkins - a champion of protection - who has been conducting an early trial of the new Sonicare ProtectiveClean brush amongst 70 of his patients. He was joined by dental hygienist Anna Middleton and together they presented the findings of a countrywide trial, demonstrating the strengths of Sonicare technology and what this means for the continued improvement of patients' oral hygiene.

The new affordable range fits well with his inclusive ethos as Dr Atkins runs oral healthcare initiatives amongst patients from all walks of life, including homeless individuals and very high-needs patients, and so accessibility is at the heart of all he does. His award winning Revive group of dental practices in the north west of England have developed a traffic light scheme to identify patients who need to tackle their oral health status and they are encouraged to adopt a better oral health routine by being provided with Sonicare brushes at cost price - because in the opinion of Dr Atkins 'You can't put a price on good oral health and I am not looking for a means of profiting from patients' improved oral status'.

For more information, visit www. philips.co.uk/dentalprofessional or call 08000567222 . 